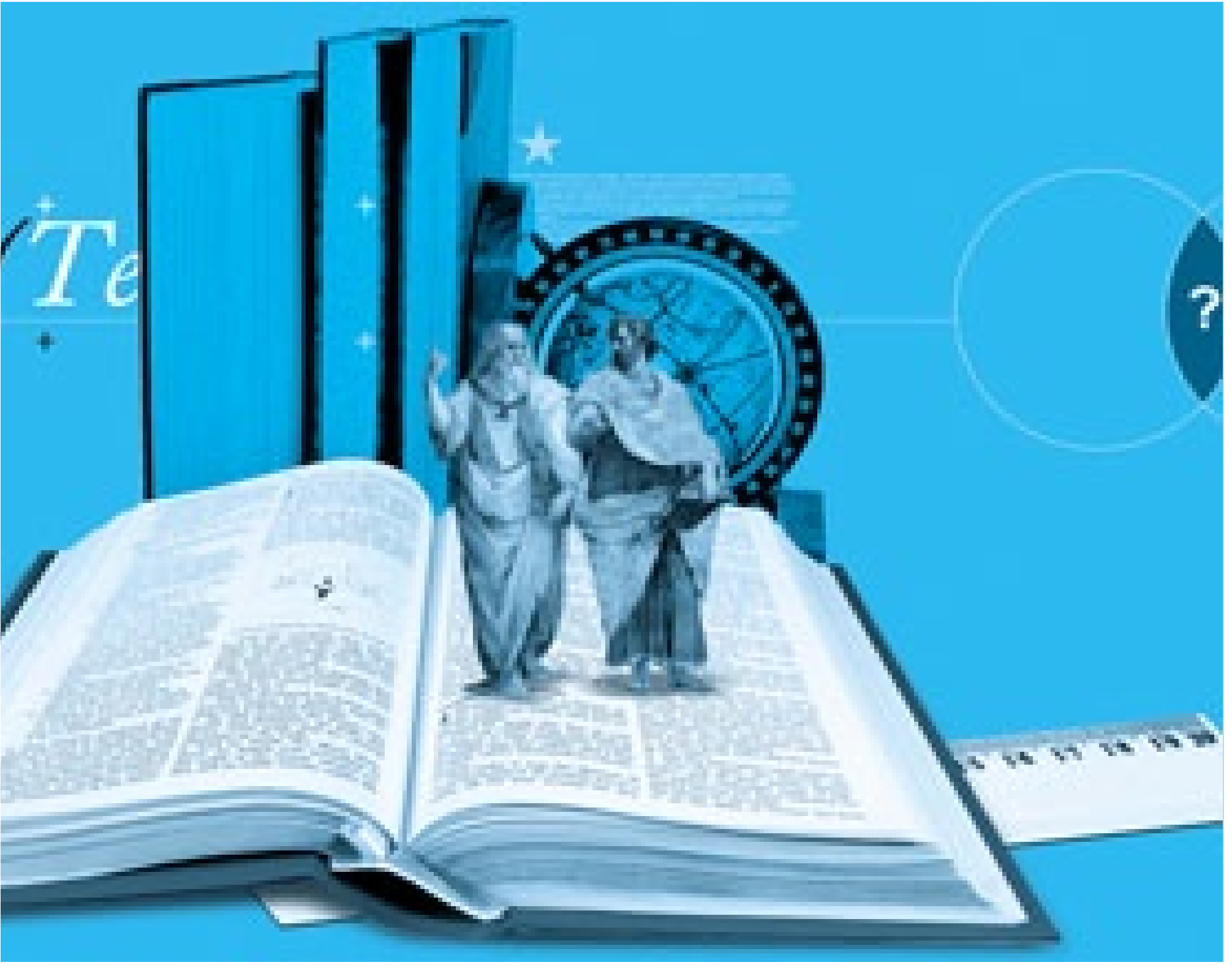

\title{
Currículo Base del Sistema Educativo Plurinacional ${ }^{1}$
}

MINISTERIO DE EDUCACIÓN, ESTADO PLURINACIONAL DE BOLIVIA 


\section{Currículo Base del Sistema Educativo Plurinacional}

\section{Resumen:}

Todo proceso histórico de cambio propone también su propia manera de educar. Hoy podemos decir que promovemos, bajo un largo proceso dialogado y consensuado, un nuevo Modelo Educativo Socio-Comunitario- Productivo que recupera la memoria y experiencias históricas de los pueblos y naciones indígenas originarias y las grandes reivindicaciones del pueblo boliviano. Se inicia una etapa en la educación boliviana con la construcción de un nuevo Modelo Educativo que articula más que divide, complementa antes que diferencia, consensua antes que impone, partiendo de un análisis crítico de la realidad histórica de la educación boliviana y de las experiencias educativas, surgen los elementos para la construcción del Currículo del Sistema Educativo Plurinacional.

\section{El Sistema Educativo Plurinacional} está fundamentado en las bases y fines de la educación boliviana descritos en la Ley Avelino Siñani - Elizardo Pérez; sus fundamentos ideológico, filosófico, sociológico, epistemológico y psicopedagógico, son los pilares de la propuesta y estructura curricular y determinan el fin de la educación, los objetivos generales y los lineamientos del sistema de evaluación. Este documento propone lineamientos generales del nuevo Modelo Educativo para facilitar su construcción y consolidación, desarrollando el componente curricular.

\section{Palabras clave: Modelo Educativo} Socio-Comunitario- Productivo, memoria indígena, educación en Bolivia, construcción de currículo, estructura curricular.

\section{Base Curriculum of the Educational System Multinational}

\section{Abstract:}

All historical process of change also proposes its own way of educating. Today we can say that we are promoting, under a long dialog and consensus process, a new educational model Socio-Comunitario - Productive that retrieves the memory and historical experiences of indigenous peoples and nations originating in and the great demands of the Bolivian people. Begins a new stage in the Bolivian education with the construction of a new educational model that articulates more that divides, complements before that difference, then consensus before it imposes, based on a critical analysis of the historical reality of the Bolivian education and the educational experiences and arise the elements for the construction of the curriculum of the Educational System multinational.

Plurinational The educational system is based on the databases and the end of the Bolivian education described in the Law Avelino Sinani - Elizardo Perez; its foundations ideological, philosophical, sociological, epistemological and educational psychology, are the pillars of the proposal and curriculum structure and determine the purpose of education, the general objectives and guidelines of the evaluation system. This document proposes general guidelines of the new educational model to facilitate the construction and consolidation, developing the curricular component.

\section{Keywords: Educational Model} Socio-Comunitario - Productive, indigenous memory, education in Bolivia, construction of curriculum, curriculum structure.

\section{Currículo Base do Sistema Educativo Multinacional}

\section{Resumo:}

Todo o processo histórico de mudança também propõe a sua própria maneira de educar. Hoje podemos

dizer que estamos promovendo, no âmbito de um diálogo e consenso processo longo e um novo modelo educativo Socio-Comunitario - produtivos que recupera a memória e as experiências históricas de povos e nações indígenas originários e as grandes demandas do povo boliviano. Começa uma nova fase na educação boliviana com a construção de um novo modelo educacional que articula mais que divide, complementa antes dessa diferença, então um consenso antes de se impõe, com base em uma análise crítica da realidade histórica da educação boliviana, as experiências educativas e surgem os elementọs para a construção do currículo do Sistema Educativo multinacional.

Plurinacional do sistema educacional é baseado nas bases de dados e ao final da educação boliviana descrito na Lei Avelino Sinani - Elizardo Pérez; seus fundamentos ideológicos,

filosóficos, sociológicos, epistemológicos e psicologia educacional, são os pilares da proposta e currículo estrutura e determinar a finalidade da educação, os objectivos e as orientações gerais do sistema de avaliação. Este documento propõe as linhas gerais do novo modelo educacional para facilitar a construção e a consolidação e desenvolvimento do componente curricular.

\section{Palavras chave: Modelo}

Educacional Socio-Comunitario produtivo, memória indígena, da educação da Bolívia, a construção do currículo, estrutura de currículo. 
“... no fui a machacar el alfabeto ni tener encerrados a los alumnos en un recinto frente al silabario. Fui para instalarles una escuela activa, plena de luz, de sol, de oxigeno y de viento, alternando las ocupaciones propias del aula, con los talleres, campos de cultivo y construcciones”.

ELIZARDO PÉREZ (1892 -1980)

\section{Caracterización general de la educación en Bolivia}

\section{Educación comunitaria en las culturas indígenas originarias}

La educación desarrollada en los pueblos indígenas originarios, cuya presencia es anterior a la colonia, fue diversa. Esta diversidad estuvo marcada par la diferenciación histórica y geográfica de cada cultura, así por ejemplo las culturas de tierras bajas desarrollaron procesos educativos acordes al entorno y actividades tales como la pesca, la caza la recolección de productos silvestres y la agricultura, a partir de las cuales se desarrollan sistemas simbólicos específicos de transmisión cultural.

La prolongación de una memoria común se basaba en la transmisión de los hechos pasados, las personas que los protagonizaron y su articulación con el mundo espiritual. En estos procesos de transmisión cultural el rol de los ancianos es protagónico. Por otro lado, los aprendizajes específicos en torno a las actividades productivas se desarrollan mediante la práctica y Ia experimentación. EI sentido de estos procesos de aprendizaje se sustentaba en mitos que expresan la cosmovisión biocentrica donde de la vida en sus relaciones multidimensionales prima sobre los intereses y necesidades humanas particulares. Estos procesos educativos estuvieron altamente asociados a la "socialización territorial” (Zambrana, A., 2009).

Las culturas de tierras altas se articularon a partir del manejo vertical de pisos ecológicos, generando procesos educativos centrados en la vida comunitaria, el intercambio y la reciprocidad. La educación, impartía complejos procesos productivos: ya en las comunidades andinas una forma de escritura estaba vinculada a las expresiones textiles producidas con el vellon; los kipus y los textiles eran las representaciones de comunicación e interpretación del mundo. La oralidad y la textualidad en la que la memoria tiene una función central, eran formas de enseñanza cimentadas en la vida de las comunidades y empleadas tanto para narrar la historia como para informar sobre nociones de terreno, identidad, las relaciones sociales, calcular aspectos de la relación con la naturaleza y los animales, el cosmos y la presencia viva de la espiritualidad" (Arnold, D. y otros., 2004). Las formas de aprender y enseñar estas prácticas textuales y orales estaban basadas en la enseñanza comunitaria $\mathrm{y}$, por tanto, en las formas de la organización y reproducción social de la propia comunidad.

En el tiempo del incario además se constituyeron otras formas de aprende y enseñar que dedicaron un espacio y tiempo específicos a los procesos de enseñanza aprendizaje. Tales formas estuvieron materializadas en las yachay wasi, espacios incaicos construidos y mantenidos para la enseñanza de idiomas, la ritualidad, y lo que hoy podríamos denominar como la astronomía y la ingeniería (Espinoza, W., 1987). Esta forma educativa tampoco estuvo alejada de la vida cotidiana y de las necesidades que ella genera, era integral, en el sentido de que quienes se educaban en estos espacios aprendían para validar inmediatamente lo que les fue enseñado (sistematización de la práctica), poniendo su conocimiento al servicio de las necesidades del incario y de las comunidades y pueblos que lo componían.

En ese sentido, el horizonte común de estos procesos educativos era que, además de ser integrales, intrínsecos a la vida cotidiana (a sus aspectos organizativos, políticos y productivos), eran por tanto, comunitarios, es decir que había una participación de toda la comunidad, además de la búsqueda de una relación armónica y complementaria (de constante del equilibrio con la Madre Tierra [naturaleza]), con el cosmos y el mundo espiritual. En otras palabras, la posición central de la comunidad era la base constitutiva de los procesos educativos en la vida de las mujeres y hombres de los pueblos indígenas originarios.

\section{La educación en el coloniaje}

La colonización de América instauró una serie de mecanismos que, además de servir para asegurar el dominio político-militar, también implicaron una modificación y re-significación de las principales ex- 
presiones sociales en torno a la matriz cultural de los pueblos indígenas originarios del continente; sin embargo, esto no significó la desaparición de su identidad. La resistencia cultural impuso también una serie de estrategias de re-significación y apartamiento que ayudaron a preservar la matriz cultural de nuestros pueblos y naciones.

No se puede pasar revisión de estos procesos educativos sin enmarcarlos en la estructura colonial instaurada por la conquista, que en el fondo se trató de una relación económico-política. Por tanto, los procesos educativos no tenían sino el fin de legitimar el dominio colonial y reconfigurar la cultura de los pueblos indígenas originarios hacia el referente europeo, en beneficio económico de la corona española. En ese entendido, se desarrollaron dos tipos de educación que respondían a la diferencia política (y de derechos) de los estatus de colonizadores y colonizados.

Para los hijos de españoles, criollos y mestizos acaudalados (ni mujeres, ni indígenas se contaban como población educable), y para la aristocracia originaria también acaudalada"2, existía la escuela de primeras letras (leer, escribir y contar), la denominada la escuela de gramática (historia sagrada, literatura, aritmética, historia profana, filosofía) y la universidad o el seminario. AI menos uno de los cronistas e intelectuales quechuas más reconocidos, perteneciente al linaje y la aristocracia inca, conocido como Garcilaso de la Vega, habría estudiado en alguna escuela particular para españoles e hijos de nobles (Escobari de Querejazú, L., 2009)”.

Para los pueblos indígenas originarios se establecieron al menos tres modalidades educativas. Al inicio de la colonia la educación para los indígenas estaba dirigida por frailes o curas que representaban la misión evangelizadora de la Iglesia católica a través de la catequización de los indígenas adultos mediante el bautizo, las confesiones y el matrimonio. La catequización además implicaba el reconocimiento del Rey de España como soberano de las tierras conquistadas y reflejaba la unidad económico-política-religiosa del dominio mercantil - imperial - misionero de la conquista. La iglesia católica había recomendado a sus frailes la enseñanza del catecismo en las lenguas

\footnotetext{
2 Durante las primeras décadas del dominio español fue creado el Liceo de San Francisco de Borja, Cuzco, al que asistían sobre todo los descendientes del linaje Inca, entre los que se puede contar, por ejemplo, a Gabriel Condorcanqui - Tupac Amaru-.
}

originarias; si bien este hecho contribuyó en parte a la conservación de los idiomas más difundidos, aymara, quechua y guarani, no deja de tener un carácter eminentemente colonial.

La segunda modalidad tiene relación directa con una acción de reordenamiento político administrativo y territorial como fue la encomienda. A través de ella se intento que la autoridad (el Encomendero), nombrada por el Rey de España para ejercer control (sobre todo impositivo) en un determinado territorio que concentraba a las comunidades (en el caso del altiplano), congregara a los indígenas originarios en reducciones (en el caso de tierras bajas)"3, y se encargara de "educar", a través de un tutor, profesor o cura que debía mantener a los miembros los pueblos y naciones originarias. Esta acción casi nunca fue efectiva. Las encomiendas fueron aplicadas ya a principios del siglo XVII y finales del siglo XVIII, y estaban siendo sustituidas por el sistema de corregimientos y luego por las intendencias. Probablemente la insurgencia indígena de quechuas y aymaras de finales del siglo XVIII, encabezadas por Tupac Katari, los hermanos Katari y Tupac Amaru, haya provocado el retorno de la preocupación española respecto a la "educación” de fos indígenas, transfiriendo nuevamente esta tarea a la iglesia católica.

Se utilizó la enseñanza del catecismo, y a través de él un rudimentario castellano para "colonizar almas", proceso de subjetivación que tuvo el sentido de consolidar la colonización política y económica. A diferencia de la opción más elitista de la enseñanza en aymara (Arnold, D. y otros., 2004), propiciada por recomendación del Concilio de Trento, esta vez, la Iglesia tenía el empeño de enseñar a los indígenas en y desde la cultura española y cristiana. Esta forma que pretendía masificar la cultura colonial tampoco se arraigó o extendió como hubieran querido sus promotores, debido a la resistencia de las comunidades (Choque, R. 1992).

La tercera forma educativa en la colonia es consecuente con estas dos últimas razones. En las comunidades y pueblos indígenas originarios, a pesar de la labor

\footnotetext{
En el caso de las misiones y reducciones en tierras bajas, hubo una mayor influencia de una educación efectiva en la "conquista espiritual" y en el "control ideológico" de los pueblos indígenas que vivían en tales espacios. En 1750 los indígenas "reducidos" eran más de 30 mil. Se recomienda ver: Puente R., 2011, Recuperando la memoria. Una historia crítica de Bolivia. Tomo 1. La Paz, Colonia Piraí, p. 36.
} 
catequista de la iglesia o la instructiva del ejército y la escuela, se continuaba reproduciendo la identidad y sus sentidos más importantes a través de la educación del propio pueblo indígena originario, una educación altamente práctica y significativa, que surgía de la propia comunidad y cuyo objeto era la conservación y desarrollo de la misma. Esta forma educativa subalterna se mantuvo a lo largo de toda la colonia y la República, aunque su grado de despliegue fue obstaculizado debido a su propia situación de subalternidad. Sin embargo, también, y no pocas veces, estas formas educativas se superpusieron y la escuela colonial sirvió a los pueblos indígenas originarios en la lucha por la conservación y recuperación de tierras y su identidad (Choque, R. 1992).

\section{Educación en la época republicana}

\section{Educación en siglo XIX}

EI Decreto del 11 de diciembre de 1825, impulsado por Simón Rodríguez, considera la educación como el primer deber del gobierno, por ello se establece la necesidad de fundar Escuelas de Ciencias y Artes en cada ciudad capital del Departamento que instruía en educación primaria y estaba abierta tanto a niñas como a niños. En 1826 se promulga el Plan de Educación Popular, mediante el cual se establecen escuelas primarias, secundarias y centrales ${ }^{4}$, colegios de ciencias y artes, un instituto nacional, sociedades de literatura y maestranzas de artes y oficios. Paralelamente al desarrollo de la libertad de enseñanza, hacia 1870 las municipalidades se hacen cargo del funcionamiento de las "escuelas de primeras letras". También durante la segunda mitad del siglo XIX, se fundaron institutos de artes y oficios, se establecieron escuelas parroquiales y escuelas elementales y superiores.

\footnotetext{
${ }^{4}$ En la escuela primaria se debía enseñar a leer y a escribir por el método de la enseñanza mutua, así como los rudimentos de la religión, de la moral y de la agricultura. En las capitales de provincia, además de la primaria, se debían establecer escuelas secundarias para perfeccionar la lectura y la escritura, la religión y la moral; se debían impartir rudimentos generales de la gramática castellana, las cuatro reglas de aritmética, la agricultura, la industria y veterinaria. En las capitales de Departamentos, además de las mencionadas, se debían establecer escuelas centrales para enseñar la aritmética, la gramática, el dibujo y el diseño.
}

EI gobierno de Agustín Morales dicta la Ley del 22 de noviembre de 1872 declarando la enseñanza libre en los grados de instrucción media y facultativa, aspecto que afectó a las escuelas elementales y primarias, que pasaron a ser administradas por las municipalidades. En consecuencia, esta Ley impulsó las iniciativas privadas y particulares para la enseñanza en los niveles secundario y facultativo. Otra de las disposiciones que afecta a la educación en este período es la Ley de 1874, sancionada en el gobierno de Tomás Frías, que ordena el funcionamiento de la Reqlamentación del Estatuto General de instrucción. Ambas leyes son cuestionadas por otorgar a las municipalidades la regencia de la instrucción primaria junto con sus recursos.

Esa situación se prolongó en los siguientes años; durante la Guerra del Pacífico las medidas del gobierno produjeron un caos en la educación: el Ministro de Justicia, Culto e instrucción Pública, Julio Méndez, emitió un Decreto aprobado en marzo de 1879 que retornaba la enseñanza secundaria privada. Entre los años 1878 y 1885, la educación escolar fue afectada por la Guerra del Pacífico porque los fondos destinados a la instrucción Pública pasaron a engrosar las finanzas de la Guerra, provocando así el cierre de las escuelas municipales y de los colegios oficiales. Por otro lado, en este período uno de los objetivos de la educación fue inculcar en los niños y los jóvenes cuatro elementos considerados indispensables para la formación educativa: escribir, leer, contar y orar.

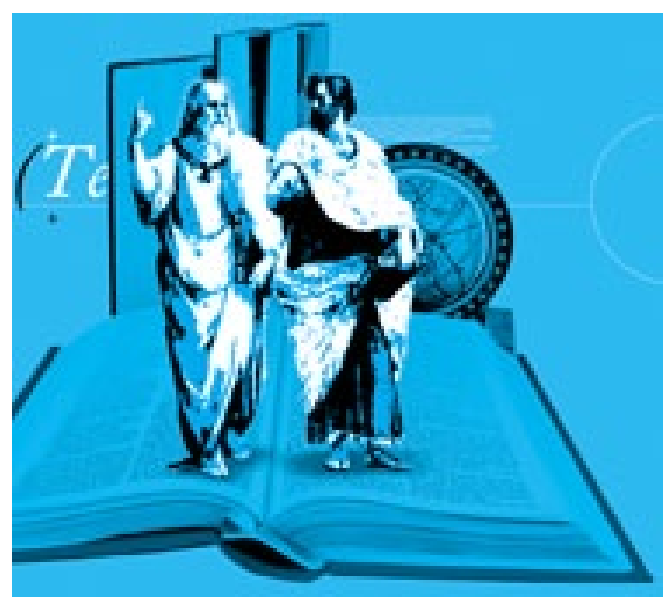




\section{6 Se utilizó la enseñanza del catecismo, y a través de él un rudimentario castellano para "colonizar almas", proceso de subjetivación que tuvo el sentido de con- solidar la colonización política y económica.}

\section{Educación en el siqlo XX}

A principios del siglo XX se produjo la primera reforma educativa, impulsada desde 1904 por el Presidente Ismael Montes. Esta reforma tuvo como motivación central la modernización del país a través de una ideología liberal. Para ello, se contrató al pedagogo belga Georges Rouma, quien proyectó las bases fundamentales de este proceso y dirigió desde 1909 la Escuela Normal de Profesores de la República de Sucre. Los aportes del pensamiento pedagógico de Rouma fueron una de las bases para el desarrollo educativo boliviano durante el siglo XX. ÉI veía el proceso de educación con un enfoque integral del ser humano, como un ser bio-psico-social, desde una perspectiva interdisciplinar de las ciencias en la pedagogía, a partir de ocho principios básicos: educación laica, co-educación, política educativa, educación práctica, científica, activa, integral y estética. Con ellos se buscaba Ia formación de un pensamiento crítico y analítico, fueron puestos en práctica durante los gobiernos liberales en Bolivia.

Posteriormente, en 1915, se fundaron tres escuelas normales rurales en Umala (La Paz), Sacaba (Cochabamba) y Puna (Potosi). A pesar de los esfuerzos para mejorar la educación, ninguna de estas instituciones beneficiaba directamente a los campesinos y a los indígenas. Esto motivó que el Presidente Hernando Siles proclamara la "cruzada nacional pro indio", porque la presencia indígena en el Estado significaba el retraso en su desarrollo, por tanto, la cruzada estaba orientada a civilizar al indio, el plan fracasó debido a las condiciones sociales existentes y a la oposición de los gamonales de entonces.

\section{Escuelas indigenales}

A fines del siglo XIX y principios del XX, sin apoyo alguno, los indígenas crearon escuelas clandestinas para aprender a leer y escribir, conformando un espacio de resistencia comunitaria frente a los gobiernos liberales de turno y la expansión del latifundismo. Estos esfuer- zos fueron reprimidos por latifundistas, autoridades y vecinos de los pueblos. Paralelamente, desde el Estado se establecieron otro tipo de escuelas dedicadas a la enseñanza de la lectura y escritura. En 1905, el gobierno liberal de Montes promulgó una Ley que establecía la creación de Esceulas Ambulantes para las comunidades indígenas. En este tipo de escuelas los maestros tenían derecho a una recompensa pecuniaria por alumno, de cualquier sexo, que llegue a leer y a realizar las cuatro operaciones de aritmética, conocer la doctrina cristiana y hablar español.

A partir de 1914, los caciques se ocuparon de gestionar ante las autoridades la instalación de escuelas indigenales que debían ser sostenidas por el Estado o por las propias comunidades. Resultado de ello, en 1920, Marcelino Lianqui, destacado Cacique y profesor ambulante, instala dos escuelas indigenales en Jesús de Machaca. Así mismo, en 1930, Eduardo Leandro Niña Quispe, funda la Sociedad República del Qullasuyu5, lIegando a dirigir ocho escuelas indigenales en diferentes cantones del Departamento de La Paz. En la provincia Umasuyus, el Cacique apoderado, Rufino Willka, se

\footnotetext{
La importancia política de las escuela indigenales radica en su origen como estrategia política ligada a la defensa legal de las tierras comunitarias y a la resistencia contra la expansión del latifundio; por ello, en 1934, Eduardo Leandro Nina Quispe, como Presidente de la Sociedad Centro Educativo Collasuyo, a tiempo de hacer las solicitudes de deslinde para las comunidades andinas, incorporó en su solicitud a los pueblos indígenas guaraní, mojeño y chiquitano, de los departamentos de Santa Cruz, Tarija y Beni. De esta orientación derivó la consolidación de los núcleos (fundados entre 1931 y 1936) Warisata en la Provincia Omasuyos, Departamento de La Paz; Moré en Itenez, Beni; Chapare en Chapare, Cochabamba; Casarabe en Moxos, Beni; Podcoyo en Nor Cinti, Chuquisaca; Cañadas en Cochabamba; Parapetí en la Cordillera, Santa Cruz; Huacharecure en San Ignacio de Moxos, Beni; Tarucachi en Carangas, Oruro; Mojocoya en Zudañez, Chuquisaca; Llica en Potosí y Canasmoro en San Lorenzo, Tarija. Estos hechos se ligaron a procesos de formación ideológica y política.
} 
ocupó de instalar escuelas indigenales en la región de Acacachi, de la cuales surgió la Escuela Ayllu de Warisata. Paralelamente a Warisata, Caiza "D” en Potosi, aportó con el enriquecimiento del concepto y procedimiento del sistema Nuclear, Seccional y la formación de educadores de extracción campesina, que plasmaría en la célebre normal indígena. Las escuelas indigenales cumplieron funciones sociales como: la reproducción de la vida comunitaria, su vinculación a la escuela; y el fortalecimiento de la identidad a través de un aprendizaje activo, reflexivo, creativo y transformador.

\section{Escuela Ayllu de Warisata}

En 1931 Elizardo Pérez y Avelino Siñani impulsaron la educación indigenal, al fundar la Escuela Ayllu de Warisata, que además de constituirse como un proyecto educativo, fue una respuesta audaz en beneficio de las comunidades indígenas y un modelo de lucha contra la exclusión, explotación y sometimiento. La "comunidad educativa" estaba conformada por maestros, amautas, niños, niñas, jóvenes, abuelos y abuelas, y sus actividades educativas estaban vinculadas a la vida, el trabajo y la producción ${ }^{6}$. Esta experiencia configuró una estructura social-comunitaria de educación y se constituyo en un paradigma educativo de liberación ${ }^{7}$ que trascendió las fronteras internacionales, aplicándose en países como México, Perú, Ecuador y otros. Desde el punto de vista Pedagógico. Warisata promovió los fundamentos de una escuela única basada en una enseñanza con enfoque productivo.

Los principios fundamentales de la experiencia de Warisata fueron:

\footnotetext{
6 “La misión”, como afirma Elízardo Pérez, “...consistía en profundizar la búsqueda y la revitalización de las instituciones ancestrales". En ese horizonte reconstituyeron el Ulaka (Parlamento Amawta); con esta institución, la experiencia de la Escuela-Ayllu se convirtió en una pedagogía paradigmática, estableciéndose el vínculo entre la educación y la organización política y social.

7 Los aportes de Warisata influyeron en la fundación de normales rurales en todo el país. Como consecuencia de ello, en 1936 se efectúo el primer Congreso de Maestros Indigenistas, en el cual se aprobaron los principios y reglamentos que dieron lugar a la creación de las Normales Rurales y el funcionamiento de las escuelas rurales diseminadas en todo el país.
}

- Reconstruir los valores comunitarios del ayllu, promoviendo una escuela productiva basada en la cosmovisión de los indígenas.

- Formación y producción artesanal.

- La escuela del trabajo productivo, social y creador de riqueza para beneficio de la comunidad.

- Fortalecer la identidad cultural de los niños, niñas, adolescentes, jóvenes y adultos, despertando su conciencia crítica y activa.

- Adecuar el calendario escolar a las actividades agrícolas y pecuarias.

- Practicar la ayuda mutua y cooperativa, consolidando la participación comunitaria en la dirección de la escuela a través del parlamento Amauta.

- Garantizar el crecimiento integral de la comunidad ${ }^{8}$.

- Promover la vinculación de la escuela con la comunidad para fortalecer el aprender produciendo.

- Alimentación e higiene como base del desarrollo mental.

\section{Primer Congreso Nacional Indígena}

La Guerra del Chaco influyó en la dinámica social, política, económica y cultural del país. El pensamiento de la juventud de la postguerra estuvo orientado a educar a las masas campesinas. Así mismo, la Asamblea Constituyente de 1938, denominada la Convención Nacional, configuró las reformas que recién se terminaban de plasmar en nuestra actual Constitución como el reencuentro entre poblaciones y territorios que antes estaban marginados; sin embargo, ambos acontecimientos dieron paso al establecimiento del Primer Congreso Indigenal $^{9}$.

Este evento, realizado en 1945, fue producto de varios congresos regionales y de otros esfuerzos organizativos de los indígenas. El Congreso se inauguró con

\footnotetext{
8 La escuela fue el lugar en el cual se trataban los problemas legales y las relaciones de grupos, se tomaban decisiones de interés general, se realizaban actividades de asistencia médica y sanidad básica, se promovía la organización de actividades deportivas y culturales; era el lugar para asesorar las labores agrícolas y ganaderas, y, en general, el espacio donde bajo la dinámica de la vida comunitaria se resolvían los más disímiles problemas cívicos, políticos, familiares, económicos y hasta sentimentales.

9 Se eligió a la directiva del Congreso, nombrándose presidente a Francisco Chipana Ramos, Vicepresidente a Dionisio Miranda y Secretario General a Desiderio Cholina, representantes aymara, quechua y del oriente respectivamente.
} 
la presencia del Presidente de la República, Gualberto Villarroel, y más de un millar de delegados indígenas del país. Se organizaron cuatro comisiones que trataron los proyectos para la abolición del pongüeaje y el mitanaje, la reglamentación de servicios personales y la educación indigenal o campesina.

\section{Código de la Educación Boliviana}

La Revolución de 1952 legitimó los derechos ciudadanos de la población marginada. Como consecuencia de la Revolución, en 1955 se pone en vigencia el Código de la Educación Boliviana, que universaliza la educación, haciéndola gratuita y obligatoria para el nivel primario, con el propósito de "modernizar" a la sociedad, bajo principios civilizatorios, homogeneizadores y nacionalistas. Este Código otorgaba a la comunidad la responsabilidad de crear escuelas. Paralelamente, de acuerdo con el Decreto Ley № 03464, Capítulo Vil, de la Reforma Agraria de 1953, se faculta a las comunidades campesinas la posibilidad de crear escuelas controladas mediante juntas escolares integradas por miembros de su organización comunal, mientras que el capítulo 141 del mismo Decreto, establecía que "dichas comunidades sostendrán los establecimientos escolares que, antes de la promulgación del presente Decreto Ley, atendían los propietarios expropiados".

Como medida complementaria al Código de la Educación Boliviana, durante el año de 1957 se promulga el Decreto Supremo № 04688 del Reglamento de Escalafón Nacional del Servicio de Educación, que norma la carrera docente y administrativa del magisterio, vigente hasta hoy. Los gobiernos de Barrientos y Banzer, establecieron la contrarreforma aI Código de la Educación Boliviana con algunas modificaciones al Sistema Educativo Nacional. Sin embargo, no hubo cambios sustanciales, sólo profundizaron la educación imperante de exclusión y discriminación de los menos favorecidos: indígenas, campesinos y sectores populares empobrecidos.

Por otro lado, gracias a la iniciativa del magisterio organizado urbano y rural, junto a la COB (Central Obrera Boliviana), se realizaron varios congresos educativos. En enero de 1970 se celebró el I Congreso Pedagógico Nacional, donde el magisterio exigió el fortalecimiento del Sistema Educativo, se promovió la descentralización administrativa de la educación y la unificación del ámbito rural con el urbano. En 1979 se celebró el II Congreso Pedagógico Nacional, que criticó la política educativa de la dictadura y reivindicó el Código de 1955, exigiendo el fortalecimiento del sistema educativo nacional sin resultados positivos.

En 1992, por vez primera, debido a una iniciativa del Estado, se realiza el I Congreso Nacional de Educación, donde participan instituciones del ámbito educativo, el sector obrero e indígena. Se atiende la necesidad de promover una educación pertinente a la diversidad, reconociendo las culturas y lenguas indígenas originarias; sin embargo, en la práctica estos avances no fueron asumidos en políticas educativas, dada la inexistencia de capacidades instaladas y la falta de decisión política de los gobiernos de turno.

\section{Ley N ${ }^{\circ} 1565$ de Reforma Educativa}

La Reforma Educativa fue parte de un paquete de medidas neoliberales del país, iniciada el 7 de julio de 1994, no loqró un cambio estructural de la educación. Los principales propósitos planteados fueron el desarrollo de una educación orientada a satisfacer las necesidades básicas de aprendizaje, la interculturalidad y el bilingüismo; adoptó como base psicopedaqóqica el enfoque constructivista, descontextualizado del medio y la realidad educativa, imponiendo una orientación individualista, humanística, modernizadora y globalizadora.

La Reforma Educativa logró construir un "tronco común curricular" para el nivel primario, con el apoyo de expertos internacionales, en un proceso que duró más de 10 años y tuvo una inversión millonaria ${ }^{10}$. La intención principal fue la de brindar atención a la diversidad cultural, estructurándose a partir de dos grandes ejes: la participación social y la interculturalidad, los mismos que debieron, aunque no lograron, transversalizar todos los procesos de aprendizaje, pues sólo se incorporaron parcialmente en el desarrollo curricular del nivel primario. Para la implementación de ese currículo se capacitó a docentes y autoridades, y se elaboró un conjunto de materiales educativos sin lograr concretar los procesos de aprendizaje y enseñanza. .

La Reforma Educativa privilegió el aprendizaje y el desarrollo de un currículo por competencias, al tiempo que la competitividad individualizada en el aprendizaje, fomentando la formación de recursos humanos como mano de obra barata para que engrosen las industrias,

\footnotetext{
${ }^{10}$ La inversión aproximada, en casi 10 años, fue de US 84 millones (Fuente Ministerio de Educación y Culturas, 2004).
} 
fábricas y empresas transnacionales privatizadas por el Estado, respondiendo a las políticas económicas del Fondo Monetario Internacional y el Banco Mundial; no se planteó articular la educación al objetivo estratégico de transformar la matriz productiva del país para superar la dependencia económica.

\section{Transición a una educación revolucionaria, democrática y cultural}

El año 2004, luego del accionar transformador de los movimientos sociales, se crean las condiciones necesarias para promover un proceso de cambio en el Sistema Educativo Nacional. En ese marco, el Ministerio de Educación y Culturas, junto al Consejo Nacional de Educación, desarrollaron eventos nacionales con talleres temáticos ${ }^{11}$ y congresos departamentales de educación, como antesala al II Congreso Nacional de Educación que no se concretó. Paralelamente, las organizaciones de los pueblos indígenas originarios campesinos $^{12}$ encontraron, durante la realización de eventos nacionales, debilidades técnicas y de gestión en la implementación de la Ley de Reforma Educativa, lo que culminó en el "I Primer Congreso Nacional de Educación de los Pueblos Indígenas Originarios”, llevado a cabo en la ciudad de Santa Cruz el año 2004.

EI año 2006 se promovieron dos medidas que dieron lugar al inicio a la Revolución Educativa, primero se creó por D.S. N ${ }^{\circ} 28725$ la Comisión Nacional de la Nueva Ley Educativa Boliviana ${ }^{13}$, que remplazó al Con-

${ }^{11}$ De educación inicial, primaria, secundaria, formación docente, alternativa, interculturalidad, participación popular y gestión institucional.

${ }^{12}$ Entre las más importantes: Consejo Nacional Ayllus y Markas del Qullasuyu (CONAMAQ), Confederación de Pueblos Indígenas del Oriente Boliviano (CIDOB), Confederación Sindical Unida de Trabajadores Campesinos de Bolivia (CSUTCB), Federación Nacional de Mujeres Campesinas de Bolivia "Bartolina Sisa" (FNMCB-BS), Confederación Nacional de Colonizadores de Bolivia (CSCB) y los Consejos Educativos de Pueblos Originarios (CEPOs).

${ }^{13}$ La Comisión Nacional estuvo compuesta por 22 instituciones y organizaciones nacionales: Central Obrera Boliviana (COB), Confederación de Trabajadores de Educación Urbana de Bolivia (CTEUB), Confederación Nacional de Maestros de Educación Rural de Bolivia (CONMERB), Confederación de Estudiantes Normalistas de Bolivia (CEN-B), Confederación de Estudiantes de Secundaria de Bolivia (CES-B), Confederación Sindical Única de Trabajadores Campesinos de Bolivia (CSUTCB), y los Conse-

\section{El pensamiento de la juventud de la postguerra estuvo orientado a educar a las masas campesinas. 99}

sejo Nacional de Educación. Esta comisión conformada por 22 instituciones y Organizaciones nacionales, fue la encargada de redactar un documento de consenso sobre las nuevas políticas educativas, cuyos resultados fueron presentados y trabajados en el II congreso $\mathrm{Na}$ cional de Educación, realizado en la ciudad de Sucre, donde participaron 33 organizaciones e instituciones nacionales de la sociedad civil. Del resultado de ambas acciones históricas, que contaron por vez primera con la participación de representantes de los pueblos indígenas y sectores excluidos, emergió el proyecto de Ley de Educación "Avelino Siñani -Elizardo Pérez”.

A partir de la gestión 2007, la Revolución Democrática y Cultural, promovida por el Estado, posibilitó que la Asamblea Constituyente diera curso a la implementación de la Nueva Constitución Política del Estado, y a partir de ella, Ia Revolución Educativa en tos sus niveles y modalidades; en correspondencia con el proceso de transformación de la educación, las demandas de la sociedad boliviana y las políticas de cambio impulsadas por la Revolución Democrática y Cultural, junto a los movimientos sociales, se crearon las bases y fundamentos del nuevo Modelo Educativo Sociocomunitario Productivo.

Por tanto, el Modelo Educativo que se propone tiene sustento jurídico en la Constitución Política del Estado Plurinacional de Bolivia, el Plan Nacional de Desarrollo y la Ley de Educación "Avelino Sañani Elizardo Pérez"14 , y orienta el desarrollo de una educación descolonizadora, revolucionaria, antiimperalista,

jos Educativos Aymara (CEA) y de la Nación Quechua (CENAQ), Federación Nacional de Mujeres Campesinas de Bolivia-Bartolina Sisa, (FNMCB-BS), Comité Ejecutivo de la Universidad Boliviana (CEUB), Confederación Universitaria Boliviana (CUB), Confederación de Empresarios Privados de Bolivia (CEPB), Confederación de Trabajadores.

${ }^{14}$ La Ley No 70 Avelino Sañani - Elizardo Pérez, fue promulgada el 20 de diciembre del año 2010. Con los nuevos lineamientos de la política educativa, expresados en la nueva Ley, se normarán y reglamentarán la estructura curricular, la gestión educativa y la participación social, de modo que la educación se vincule desde, para y con la producción, ajustándose a las características culturales. 


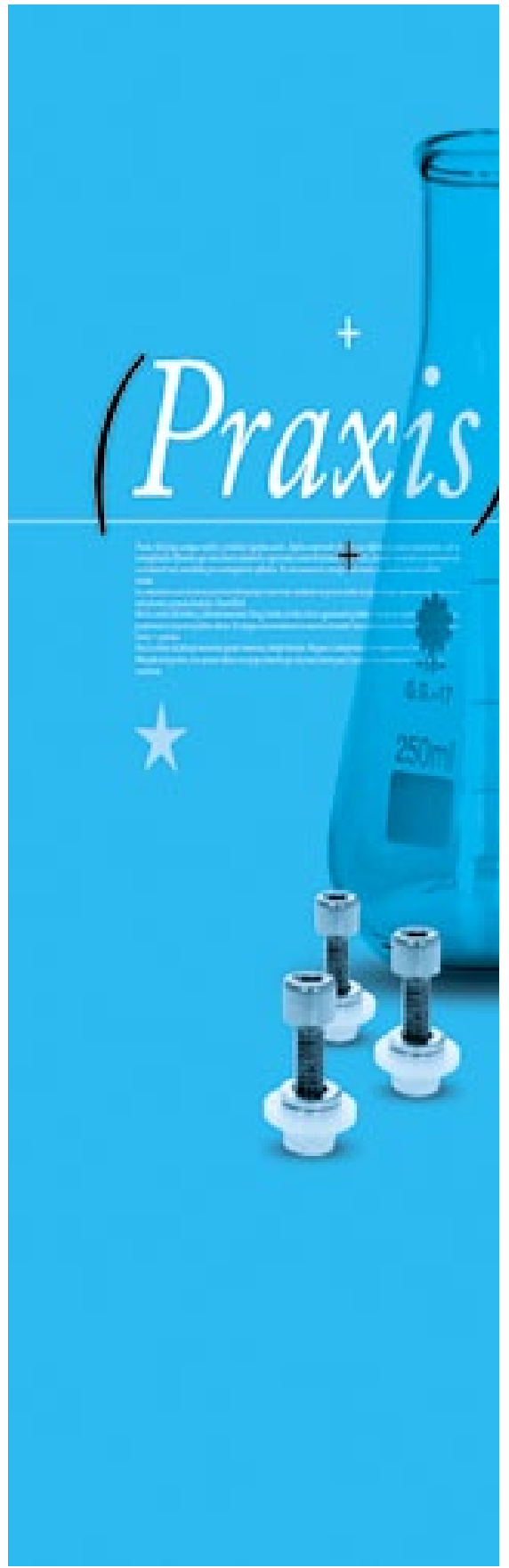

liberadora y transformadora de las estructuras sociales inequitativas y de la matriz productiva del país; una educación de resistencia a la homogenización para hacer frente a la crisis civilizatoria del capitalismo.

\section{Currículo base del nuevo modelo educativo}

\section{Realidades a las que responde el modelo socio-comunitario productivo}

La construcción de un nuevo Modelo Educativo responde a una lectura crítica de la educación boliviana, porque éste debe expresar claramente las insuficiencias, los aspectos obviados o relegados en los anteriores modelos educativos, y sus subsecuentes propuestas curriculares. EI nuevo modelo educativo responde a cuatro problemáticas que no fueron tomadas en cuenta por las anteriores propuestas educativas:

La condición colonial y neo colonial de la educación se expresaba en la sobrevaloración de lo foráneo en desmedro de las potencialidades internas, imponiendo contenidos enajenantes y descontextualizados que, además de promover la imitación de estereotipos de otras culturas, desarrollaba una mentalidad copista, repetidora y mecanicista.

La desestructuración de la mentalidad colonial no forma parte de las propuestas educativas anteriores ${ }^{15}$, por lo que el desprecio de las culturas propias, la exclusión y la discriminación continuaron, frenándose la trasformación de las realidades ${ }^{16}$.

La condición colonial y neo colonial de la educación se expresaba en la sobrevaloración de lo foráneo en desmedro de las potencialidades internas, imponiendo contenidos enajenantes y descontextualizados que además de promover la imitación de esterotipos de otras culturas, desarrollaba una mentalidad copista, repetidora y mecanicista.

\footnotetext{
${ }^{15}$ Lo que no quiere decir que se desconozcan esfuerzos pasados como la escuela de Warisata o las escuelas indigenales, o presentes, como los realizados por profesores y profesoras que aún hoy intentan romper esa lógica; sin embargo, podemos advertir que como parte de una política de Estado es muy poco lo que se hizo al respecto.

${ }^{16}$ Se recomienda ver Paulo Freire, 1970, Pedagogía del oprimido, México, Siglo XXI; y Pedagogía de la esperanza, 1993, México, Siglo XX.
} 
La mentalidad colonial del presente, también incorporada en los sistemas de enseñanza aprendizaje, hizo que la brecha entre teoría y práctica se agrandara. En el aula, se partía de la ejemplificación de modelos foráneos, enseñando desde la teoría pero no con el fin de Ilegar a la práctica, y no se consideraba relevante partir de nuestras realidades. Reconociendo el hecho de que no hay posibilidad de práctica transformadora en torno a las inequidades económicas, sociales y culturales sin tomar en cuenta el contexto y las realidades de la plurinacionalidad, esta propuesta funda sus prácticas pedagógicas en la vida comunitaria.

Por último, la mentalidad colonial tiene también consecuencias institucionales, entre ellas, la incoherencia entre modelos educativos y tradiciones pedagógicas. Experiencias como la Escuela Ayllu de Warisata, las Escuelas Indígenales y otras iniciativas y propuestas no fueron tomadas en cuenta en el pasado para generar un nuevo Modelo Educativo.

Una segunda problemática institucional es la débil articulación entre las políticas educativas estatales y las propuestas para salir de la dependencia económica, la condición histórica mono productora, facilitadora de materias primas para el mercado mundial. Una educación centrada en la formación humanística, con una incipiente educación técnica, sólo ha reforzado esta dependencia económica, mediante la generación de mano de obra barata para el mercado de trabajo interno, reflejo de la división internacional del trabajo donde la dependencia económica se refuerza. Todos los caminos para profesionalizar y cualificar la mano de obra técnica, pese a sus buenas intensiones, sólo atinaron a reforzar la condición subordinada al mercado internacional, por lo tanto, fortalecieron cada vez más la dependencia de Bolivia.

El mercado de trabajo contiene una herencia colonial que sobrevalora la formación humanística por sobre la formación técnica, y la proliferación de profesionales en esta área es una muestra de ello. Por tanto, se desvalorizan los oficios técnicos, no sólo por ser menos remunerados, sino también por ser menos valorados y en algunos casos hasta considerados inferiores. La posibilidad de desestructurar la mentalidad colonial en el ámbito educativo no depende solamente de la articulación del trabajo manual e intelectual, ni del incentivo económico para generar mejores condiciones de formación técnica, sino que requiere de un accionar pedagógico que fortalezca la formación técnica hacia una formación productiva articulada a políticas econó- micas concretas, que apuntalen la transformación de la matriz productiva y la soberanía alimentaria. Bajo estas condiciones, la educación se convierte en un componente dinamizador que une la producción y reproducción de la vida y las culturas de la plurinacionalidad.

La tercera problemática se refiere a la revalorización y reconstitución de los saberes y conocimientos de los pueblos indígenas originarios, de la plurinacionalidad dada su potencialidad para generar saberes y conocimientos propios y pertinentes, abandonando la consideración de inferioridad en relación a los conocimientos y saberes denominados universales.

La educación en Bolivia relegó los saberes y conocimientos indígenas originarios, al considerarlos superados por los "avances" del conocimiento acumulado universalmente, pero también porque se los consideró locales, es decir adecuados y pertinentes a culturas particulares. Fue desde éste enfoque intercultural particularista que la Reforma Educativa planteó una educación tolerante frente a los saberes y .conocimientos indígenas originarios y, en el plano práctico, mantuvo una visión aislada y estática de las culturas, reforzando el rescate cultural particularista y la subvaloración de los saberes y conocimientos indígenas originarios en relación con el conocimiento universal. Este enfoque en torno a los saberes y conocimientos, dejó de lado el proyecto político de los pueblos y naciones indígenas originarios de Bolivia, que expresaban la necesidad de reconstituir su forma de vida luego de haber sido colonizados durante más de 500 años.

Actualmente, la re-emergencia de la visión planteada por los pueblos y naciones indígenas originarios, implica considerar sus saberes y conocimientos como suficientemente válidos ${ }^{17}$ para aprender de ellos, es decir, asumir el hecho de que también pueden ser universales. Esto implica producir conocimientos desde las culturas en igualdad de jerarquía con los conocimientos "universales", contribuyendo a reconstituir las identidades y formas de vida de la plurinacionalidad, pues a través de la producción de conocimientos se reconstituyen y re-emergen también los pueblos y

\footnotetext{
${ }^{17}$ Recientemente se ha reconocido por la OMS a los kallawayas como médicos herbolarios. Durante mucho tiempo la medicina occidental aprendió el saber y el conocimiento del manejo de las plantas de los pueblos ancestrales, lo que luego permitió el avance y el desarrollo de las industrias farmacéuticas y esto nunca fue reconocido. Hoy estamos enfrascados en una lucha sobre la propiedad intelectual de los saberes y conocimientos de nuestros pueblos.
} 
naciones relegados y calificados como "inferiores" respecto del avance de la modernidad. El aprendizaje de tos saberes y conocimientos de los pueblos y naciones indígenas originarios y la producción de conocimientos desde la cultura, genera un proceso nuevo que facilita su incorporación al nuevo Modelo Educativo y la trasformación de la realidad mediante la apropiación y desarrollo de sus potencialidades.

La cuarta problemática a la que responde la propuesta del nuevo Modelo Educativo, sintetiza todas las anteriores, pues al articular la construcción de un nuevo modelo educativo adecuado a las exigencias del Estado Plurinacional, se compromete con la trasformación de la realidad. Por ello debe considerarse que la educación ya no es sólo un proceso formativo centrado en lo cognitivo, sino que responde a las necesidades $\mathrm{y}$ resuelve las inequidades y exclusiones que vivimos. Este aspecto dinamizador es el nuevo componente que permea toda la propuesta curricular.

\section{Fundamentos del Currículo Base}

\section{Fundamentos ideológico-políticos}

Después de varios siglos de predominio colonial y neo colonial, en Bolivia estamos en curso de un proceso de descolonización que justamente implica la salida de la condición colonial, en función de una nueva alternativa o forma de convivencia inspirada en los pueblos y naciones indígenas originarios de Bolivia, para resurgir de la condición de desigualdad y explotación producidas por el capitalismo globalizado. EI coloniafismo abarca la dimensión de dominación política, económica, social y productiva, manifestándose en el ámbito material, la explotación de la fuerza de trabajo y el saqueo de los recursos; la colonialidad18 o el neocolonialismo se manifiesta en la dominación y subordinación simbólica y cultural.

\footnotetext{
${ }^{18}$ Para ampliar el concepto se recomienda revisar: Viceministerio de Descolonización. Programa de Capacitación en Descolonización para Servidoras y Servidores Públicos con enfoque de género, 2010, p. 12. Documento Inédito.
}

El nuevo currículo es descolonizador en lo material y subjetivo porque transforma las estructuras neocoloniales ${ }^{19}$, vitalizando la relación entre el individuo y la comunidad, propiciando el desarrollo de una conciencia comunitaria, de reconocimiento de las identidades culturales, legitimando los saberes y conocimientos propios, los valores socio-comunitarios, las cosmovisiones y la espiritualidad de los pueblos indígenas originarios $^{20}$, en diálogo con los saberes del mundo.

El currículo plantea una educación descolonizadora, que incorpora los valores y conocimientos de los pueblos y naciones indígenas originarios de modo igualitario, que revaloriza, recupera y despliega sus potencialidades, contribuyendo además como forma contra-hegemónica y alternativa frente al capitalismo. Además, presenta lo comunitario como forma alternativa de convivencia civilizatoria, el Vivir Bien como horizonte de vida que busca la armonía y la complementariedad con la Madre Tierra y toda forma de vida en el planeta, donde no prime la competencia individual y la racionalidad instrumental, sino una relacionalidad complementaria.

Como parte de la descolonización, en el plano subjetivo se propone la generación de una conciencia productiva, creativa y transformadora que permita la revolución cultural del pensamiento y el saber; estableciendo una educación en la comunidad de la vida y sus valores, que reconozca como protagonistas de los procesos educativos a las personas que constituyen la

\footnotetext{
${ }^{19}$ El modelo económico neoliberal en Latinoamérica ha reproducido las estructuras coloniales, generando grandes desigualdades e incrementando la pobreza. El neoliberalismo, como parte del capitalismo, está sujeto a los mercados y al libre movimiento de capitales, política que busca maximizar el bienestar individual sacando el mayor provecho posible de los recursos naturales y del trabajo que deteriora la naturaleza y pone en peligro el futuro de la vida en el planeta. Aunque el neoliberalismo pregona el libre mercado como el mejor escenario para la vida social, más allá de ser una doctrina económica, representa una concepción de la vida en sociedad, que paradójicamente produce una pérdida del sentido comunitario al promover la globalización, que uniformiza a las personas y a las culturas.

${ }^{20}$ Entendemos que los saberes y conocimientos vienen de todos los pueblos y naciones del Estado Plurinacional, que comprenden a los campesinos, comunidades interculturales, afrodescendientes, organizaciones sociales y todas las formas de expresión cultural.
} 


\section{6} Una segunda problemática institucionales la débil articulación entre las políticas educativas estatales y las propuestas para salir de la dependencia económica. 99

educación extendida en las aulas y más allá de ellas, así como también a la educación viva instalada en los entes tutelares de nuestros territorios o soporte físico y simbólico referencial de las comunidades ${ }^{21}$.

El currículo propone y articula prácticas descolonizadoras que rompan los esquemas mentales individualistas y dogmáticos, para que sean capaces de reafirmar y fortalecer sus identidades culturales propias a través de la práctica de los valores socio-comunitarios y el uso y desarrollo de las lenguas originarias. La transformación de la realidad boliviana, en sentido descoloni-

\footnotetext{
${ }^{21}$ El concepto de territorio no se reduce solamente a un espacio físico y geográfico, sino al lugar que da sentido de pertenencia a una comunidad. Para las comunidades, no sólo involucra lo organizativo, sino lo simbólico (rituales), lo jurídico (normativo) y lo tecnológico (sabiduría procesal).
}

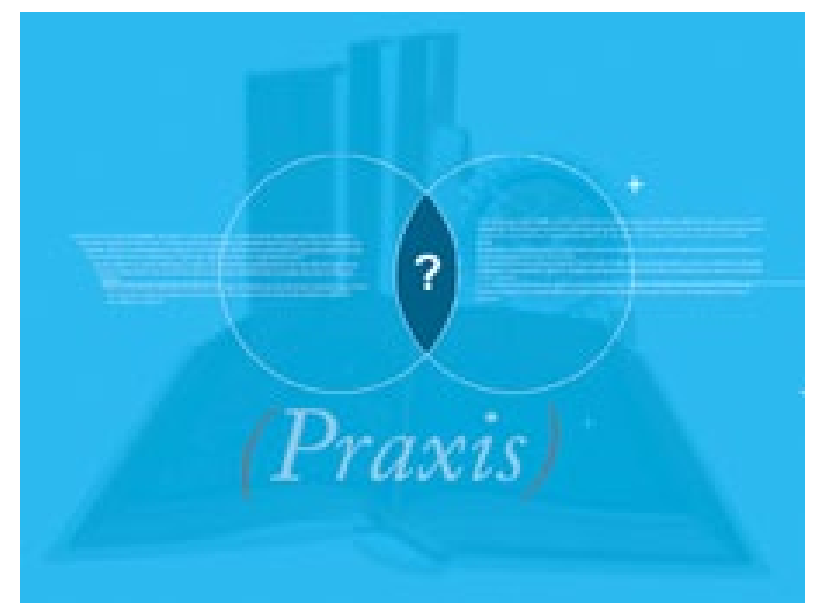

zador, tiene como uno de sus pilares la transformación de la educación, pues ella tiene un papel fundamental en la generación de un nuevo tipo de pedagogía que permita consolidar esa transformación.

\section{Fundamentos Filosóficos}

El Vivir Bien, expresado en las experiencias y prácticas de los pueblos y naciones indígenas originarios, se convierte para la nueva educación en un criterio de vida del cual emergen los sentidos de búsqueda de complementariedad y armonía con la Madre Tierra (naturaleza), los fenómenos socio-culturales y económicos, el cosmos y la dimensión espiritual de la vida. Se busca aprender a educarse en las relaciones complementarias y regidas por los ciclos de vida de los seres humanos, plantas, animales y Cosmos, promoviendo desde esta dimensión, el encuentro de perspectivas holístas para el abordaje de la salud, la educación, el trabajo y la organización social y comunitaria. A partir de la educación, se promueve la constitución de una conciencia de vida repensando el lugar que ocupa el ser humano en relación armónica con todo lo que lo rodea.

Esto nos obliga a examinar los productos que el capitalismo actual globalizado expresa como la solución a "todos" los problemas de la humanidad. Desde el Vivir Bien podemos encarar la vida de otra manera y permitir que los seres humanos aprendan y construyan alternativas inspiradas en las experiencias y prácticas de los pueblos indígenas originarios; así, la educación, antes encaminada inevitablemente al progreso, al desarrollo, a la vida moderna acelerada, al individualismo extremo, a la objetivación de la Madre Tierra, a la relación instrumental con el otro y la otra cultura, al patriarcado, encuentra alternativas inspiradas en el Vivir Bien.

El nuevo currículo, por tanto, se funda en el Vivir Bien, como la experiencia que nos orienta en el camino por recorrer en la búsqueda de resolver las necesidades de toda la población boliviana, y encontrar una alternativa en el actual momento de crisis mundial. Educarse en el Vivir Bien tiene que ver con la búsqueda de armonía con la Madre Tierra (naturaleza), que no es un respeto racional ni calculado, así como lo es por ejemplo en el desarrollo sustentable, sino que se da a 
partir del desarrollo de la conciencia holísta, donde el ser humano se piensa y siente como parte de la naturaleza y el cosmos.

La educación tiene la tarea de recuperar esa conciencia del Vivir Bien, para lo cual el conocimiento científico es insuficiente, porque la enseñanza no sólo instruye en la manipulación de objetos, el conocimiento y aprendizaje de habilidades o destrezas, sino que en un sentido profundo implica una educación de la vida, en la vida y para la vida, es allí donde adquiere sentido una educación en el Vivir Bien. El conocimiento científico, técnico- tecnológico, hoy importante para el desarrollo de la vida del ser humano, no garantiza por sí mismo una vida armónica ni complementaria.

Por eso se recupera, desde la educación, una formación que busca la complementariedad bajo un sentido de vida dialógico, es decir, de manera articulada y complementaria, también con la ciencia, e incluso con otras alternativas que se están gestando en otros lugares, y que, como elemento educativo en concreto, plantea la formación integral y holística de las y los estudiantes (niñas, niños, adolescentes, jóvenes y adultos) en interrelaciones con equidad y justicia social, desarrollando una conciencia de convivencia con la naturaleza, el cosmos y la dimensión espiritual de la vida.

\section{Fundamentos sociológicos}

Lo plurinacional ha sido históricamente, y es, la configuración de nuestra realidad; sin embargo, este hecho ha sido completamente obviado y en su lugar se ha potenciado consecutivamente la construcción de un Estado Nación monocultural (colonial), con consecuentes propuestas de educación monocultural, sin generar correspondencia con el contexto subyacente. De lo que se trata, en el proceso de transformación, es de construir un Estado Plurinacional y un Modelo Educativo de carácter plurinacional, que responda a la diversidad boliviana y que configure instituciones plurales por primera vez en nuestra historia.

Cuando menos la pluralidad de la realidad boliviana, en la que se funda el nuevo currículo, tiene tres niveles a ser considerados. En primer lugar la pluralidad, que está configurada por la coexistencia de pueblos y naciones indígenas originarias que han presentado desde tiempos pre-coloniales una gran diversidad. La reivindicación de las culturas y territorios de estos pueblos es fundamental, debido al proceso de debilitamiento y hasta de extinción que han sufrido. En términos educativos, ello exige la recuperación, uso y desarrollo de las lenguas, muchas de ellas habladas hoy por muy pocas personas.

Un segundo nivel, tiene que ver con el abigarramiento social ${ }^{22}$, que es la condición de superposición de contextos socioeconómicos: lo urbano, rural, regional, entre otros que configuran la realidad boliviana. Es preciso permitir que estos otros contextos que viven separados, divorciados o sobrepuestos, puedan incorporarse armónicamente a la construcción del Estado Plurinacional.

Finalmente, hay que considerar un tercer nivel de la pluralidad boliviana, constituido por la pluralidad identitaria y organizativa, que está constituido por otros factores que deben ser considerados en la elaboración de un currículo, como son la cuestión regional que hace que en Solivia se identifiquen diferencias notables entre regiones y en la gama de organizaciones territoriales que configuran la complejidad de esta sociedad. Este tercer nivel plantea una fuerte exigencia a la educación, en cuanto a su gestión, pues debe ser protagonizada localmente, pero también en cuanto al propio currículo, que tiene que contextualizarse según la región y localidad de cada escuela. Por ello, el Currículo Base plantea lineamientos generales que organizan la educación en Bolivia, los mismos que deben ser desplegados según la realidad de cada región, de-

\footnotetext{
${ }^{22}$ Lo "abigarrado" es una manera de referirse al tipo de diversidad de sociedades como la boliviana, noción que trabajó Rene Zavaleta Mercado. El concepto plantea que este tipo de realidades, debido a la dominación capitalista y colonial, han configurado una complejidad heterogénea que no puede ser analizada con las categorías estándar, pensadas para sociedades homogéneas, de las ciencias sociales, debido a que están compuestas por la superposición de diversos tiempos sociales, como el tiempo rural agrícola, el tiempo moderno urbano. Para ampliar el término se recomienda ver Zavaleta, R., 1994. Lo nacional popular en Bolivia. México, Siglo XXI, p. 30; Panikkar, R. 2008. La puerta estrecha del conocimiento, Barcelona, Herder; o Panikkar, R. 2009. La puerta estrecha del conocimiento. Sentidos, razón y fe. Barcelona: Herder.
} 
nominados, en la Ley Avelino Siñani-Elizardo Pérez, como el currículo regionalizado y diversificado.

\section{Fundamentos epistemológicos}

El nuevo modelo educativo se fundamenta en el pluralismo epistemológico, entendiendo por ello la articulación y complementariedad, sin jerarquías, de distintos tipos de saberes, conocimientos, ciencia y sabiduría, propios y de otras tradiciones, en un proceso de recuperación y diálogo intra e intercultural. Esto significa que no puede haber un predominio unilateral de un tipo de conocimiento considerado equívocamente como universal. La ciencia moderna, por ejemplo, puede ser muy importante para muchas actividades humanas, pero no abarca todas las dimensiones de la vida, sino sólo aspectos cuantificables, medibles, de lo "real", que no son TODA la realidad (Panikar, R., 2008). Por lo tanto, el conocimiento no se agota en la ciencia.

El conocimiento científico se considera como neutro y apto para cualquier cultura, pues aparece como universal, del mismo modo que la tecnología se considera la solución a todos los problemas, en todos los lugares, pero tiene, como todo conocimiento, sus limitaciones. Los otros tipos de conocimiento y sabiduría también tienen una gran importancia. Al recuperar la sabiduría indígena originaria, por ejemplo, con la relación espiritual con la naturaleza, no estamos retrocediendo a una visión "primitiva”, mítica, pre-científica, sino reconociendo que el ser humano no puede vivir sólo y exclusivamente a través de la ciencia. La sabiduría de muchas tradiciones culturales, y de los pueblos y naciones, posibilita no caer en las consecuencias perversas de la totalización de la ciencia.

Ha sido la pretendida desmitificación de toda la realidad propiciada por la ciencia moderna, la que ha justificado la explotación sistemática de la naturaleza, considerada puramente como un objeto, hasta el punto en que se ha puesto en peligro la vida de la Madre Tierra (naturaleza) y del ser humano, al haberse producido un desequilibrio, una crisis ecológica sin precedentes. Esto no significa que la ciencia moderna deba ser negada, sino que no puede ser el único tipo de conocimiento válido, pues requiere de su articulación con otros tipos de conocimiento, recuperados y reconocidos como igualmente válidos para responder de manera pertinente a los problemas producidos por la globalización del capitalismo.

\section{Fundamentos psicopedagógicos}

El Currículo Base se fundamenta psicopedagógicamente en el aprendizaje comunitario, es decir en un aprendizaje desde, en y para la comunidad; la comunidad es el nudo central a partir del cual la formación y el aprendizaje tienen sentido y pertinencia. Se aprende dialógica y creativamente, con un sentido comprometido y útil (ético) del conocimiento. Metodológicamente podemos establecer que el aprendizaje comunitario se concretiza en cuatro criterios de orientación metodológica:

Una educación en la práctica que se expresa en la experiencia (vivencial) y la experimentación (contacto directo con la realidad). La primera, parte de las vivencias de las y los involucrados en el proceso de enseñanza y aprendizaje, todos y todas empiezan una formación desde y a partir de sus vivencias, así se conecta la educación con su cultura desde sus experiencias. La segunda, parte de un contacto directo con la realidad desde los diferentes campos de saberes y conocimientos, para posibilitar el desarrollo y fortalecimiento de capacidades, habilidades y destrezas en espacios concretos donde se desenvuelve lo cotidiano.

Una construcción teórica que reflexione, re-semantice, elabore, sistematice y organice contenidos pertinentes y nuevos, a partir de las experiencias y la experirnentación, susceptibles y en proceso de generar un pensamiento teórico capaz de contribuir al proceso de transformación de la realidad concreta.

Un proceso valorador o de la valoración que, como resultado del momento práctico y teórico, facilite la autoevaluación deI desarrollo de las capacidades, habilidades y destrezas aplicadas a la vida en cuanto a su uso y pertinencia. La valoración, sin embargo, no está completa mientras no se vincule a la pertinencia comunitaria, es decir que debe proyectarse su utilidad para el bien común, fortaleciendo actitudes positivas hacia la transformación social, orientadas a una búsqueda de complementariedad con la Madre Tierra (naturaleza) y el Cosmos.

La producción integra la práctica, la teoría y la valoración en actividades, procedimientos técnicos y de 
operación en productos terminados, que muestren su pertinencia como parte del sentido útil del conocimiento; generando bienes tangibles e intangibles. Todos los anteriores momentos del proceso pedagógico convergen en la concreción de la producción, donde se integran creativamente los saberes y conocimientos provenientes de diferentes áreas y campos. El momento de la producción enfatiza el carácter pertinente y por tanto creativo ${ }^{23}$ del conocimiento como parte de una enseñanza desde lo concreto y útil para la comunidad.

En esta concepción, la escuela-familia-comunidadestado, son instancias de interacción, una condición necesaria para la configuración de los escenarios donde se desarrollan los procesos educativos. Por ello, la educación en la vida, entendida en toda su amplitud, opera como un centro transformador de los involucrados en el proceso de enseñanza y aprendizaje. Por tanto, los procesos educativos son de carácter práctico-teórico-valorativo-productivo, y se desarrollan en espacios productivos de enseñanza y aprendizaje, constituidos en el aula, talleres, laboratorios, gabinetes, campos deportivos, campos de producción y en el entorno socio-comunitario en general. Estos espacios se integran y complementan a partir de un sentido básico de desarrollo de iniciativas, esfuerzo, sociabilidad y responsabilidad, donde el trabajo productivo es una acción dinámica y creativa y no se reduce a una experiencia mecánica, técnica y utilitarista.

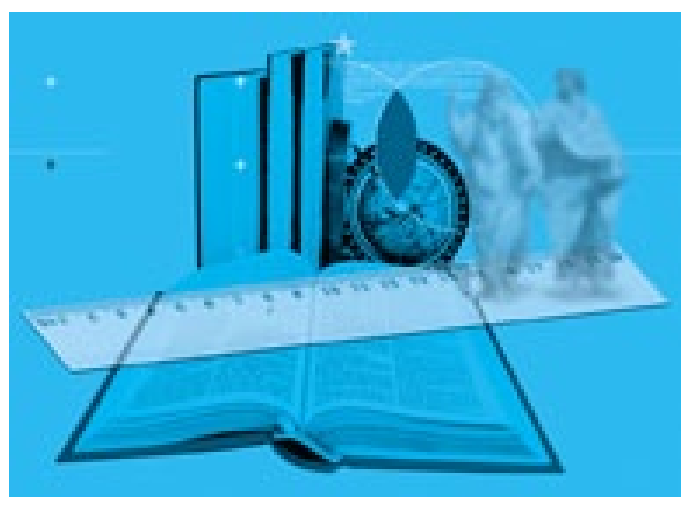

\footnotetext{
${ }^{23}$ Lo productivo en tanto no responde a una realidad específica y en el que además confluyan destrezas y habilidades aprendidas, exige necesariamente un desarrollo de la creatividad, puesto que debe ser una respuesta a una situación inédita y nueva. No se trata de lo creativo como algo absolutamente nuevo, aunque no se niega esta posibilidad, sino lo creativo como capacidad de responder a las exigencia concretas y cotidianas, enlazando la educación con lo productivo.
}

\section{Bases del currículo}

\section{Los saberes y conocimientos de los pueblos y naciones indigenas}

El currículo tiene como una de sus fuentes y bases al conocimiento, la sabiduría, saberes y valores de los pueblos y naciones indígenas originarios, desarrollados a partir de una educación comunitaria. Esta forma de enseñanza y aprendizaje se vivió como una experiencia y no tanto como una metodología sistematizada, pues estaba vinculada directamente con la vida de las comunidades.

Básicamente, se trata de una experiencia que muestra que la educación no está necesariamente separada como una institución especializada, sino que puede ser ejercitada por la comunidad en la reproducción de su vida. Toda la comunidad está empeñada en la educación, durante todo el tiempo; es más, la educación, emparentada con la crianza mutua, se amplía más allá de la esfera de los seres humanos. La comunidad no está constituida solamente por la gente, sino que también hay una relación, o más bien lo que podríamos denominar una relacionalidad comunitaria, también con la Madre Tierra (naturaleza), el cosmos y la espiritualidad. Estos son elementos que configuran la experiencia de la educación comunitaria, cuya sabiduría constituye una base fundamental del nuevo currículo de carácter plurinacional.

\section{La experiencia pedagógica de la Escuela Ayllu de Warisata ${ }^{24}$}

Warisata constituye otra de las bases del nuevo Currículo del Sistema Educativo Plurinacional; tuvo una organización social, económica y política comunitaria, fundada en las cosmovisiones y valores propios. Fue una escuela de estudio, trabajo y producción, donde se vincularon las prácticas comunitarias con los quehaceres del aula, además de ser la única y nuclearizada, integrando los diferentes niveles de formación desde la infancia hasta la educación superior.

La escuela Ayllu de Warisata desarrolló la educación de la vida, donde saber bien era una condición educativa del Vivir Bien; donde la sociedad en conjunto educa a la sociedad. En este sentido, la escuela pierde su dimen-

\footnotetext{
${ }^{24}$ Esta experiencia trascendió en todo el continente americano y desarrolló una pedagogía desde la comunidad. A su vez, la tradición de Warisata, interrumpida por el régimen oligárquico de entonces, se reencauza en el momento actual de cambio histórico, social y educativo que vive el país.
} 
sión de recinto aislado, cerrado, apartado de la sociedad y del entorno, y se transforma en una institución de vida que contribuye a la formación del ser humano con potencialidades y capacidades para aprender y desarrollarse en el mundo de hoy. Warisata se caracteriza por desarrollar una pedagogía productiva y liberadora, una educación activa y de trabajo destinado al bien comunitario. Su propuesta permite pensar y actuar con una ideología propia, a la vez que desarrollar un pensamiento crítico, creativo y propositivo, dirigido a la producción de bienes materiales, intelectuales y espirituales para el bien común.

\section{Propuestas pedagógicas críticas de Vigotski}

Otra de las bases del nuevo currículo son las propuestas pedagógicas críticas, entre las que se destaca la desarrollada por Vigotski, la cual considera que las personas aprenden en interacción con los demás, en un proceso mediado por la cultura desarrollada histórica y socialmente. A pesar de que es posible referirse a los distintos conceptos trabajados por Vigotski, la idea aquí no es basarse en todos planteamientos, sino rescatar algunos que pueden articularse, incluso resignificándose, a la educación comunitaria y productiva que propone el nuevo Currículo Base.

Entre estos conceptos se destaca el de la Zona de Desarrollo Próximo, desarrollado en parte como crítica y alternativa a la aplicación de los test estáticos individuales con que se medía la inteligencia; Vigotsky (1979), formula dicho concepto como:

“...la distancia entre el nivel real de desarrollo, determinado por la capacidad de resolver independientemente un problema, y el nivel de desarrollo potencial, determinado a través de la resolución de un problema bajo la guía de un adulto o en colaboración con otro compañero más capaz”.

Esta zona de interacción social es la más próxima al niño o niña, allí tiene la posibilidad de interactuar y aprender. Vigotski plantea que en primer lugar está la zona de relación con sus padres/madres, en segundo lugar con sus maestros/as, y por último otra zona más amplia de interacción con otras personas. En consecuencia, la zona de desarrollo próximo aporta una fundamentación importante para comprender los procesos de la constitución subjetiva y de apropiación cultural; sin embargo, esto puede variar mucho dependiendo de la cultura donde en que se vive, en la que, por ejemplo, esa zona próxima puede estar

\section{En esta concepción, la escuela-familia- comunidad-estado, son instancias de interacción, una condición necesaria para la configuración de los escenarios donde se desarrollan los procesos educativos. 99}

constituida por la familia extensa y otros miembros de la comunidad, antes que por los maestros/as. Lo importante es que en esas zonas de desarrollo próximo el niño o niña puede establecer situaciones significativas, en cuanto están directamente vinculadas con su vida, sus experiencias concretas y su cultura.

Con este concepto de zona de desarrollo próximo Vigotsky hace mención al desfase que entre la resolución individual y social de las tareas cognitivas. Para este autor, todo niño y niña tiene en cualquier dominio un "nivel de desarrollo real”, que puede ser evaluado examinando su individualidad, y cuenta además con un potencial inmediato de desarrollo dentro de ese dominio; es a esa diferencia que se denomina "zona de desarrollo potencial”. Sucede con mucha frecuencia que las personas somos capaces de resolver problemas con la ayuda de otros, sin embargo, en las situaciones en que nos encontramos solos, no somos capaces de resolver los mismos problemas; ahí radica la importancia de este concepto.

Esto es lo más importante para ser rescatado y resignificado en el nuevo currículo: el aprendizaje se logra en interacción con su comunidad mediante su experiencia cultural concreta; se logra con la ayuda, guía, colaboración y participación del/la maestro/a, la comunidad educativa y el entorno. En ese marco, el enfoque pedagógico busca formar estudiantes que interactúen y se apropien de la cultura, a partir de un proceso participativo, formativo, activo, reflexivo, crítico, integrador y comunitario, mediante el cual se aprenden procedimientos, pensamientos y formas de actuar, ligados al trabajo y la producción tangible e intangible. De esta manera, la teoría histórico-cultural de la educación concibe el desarrollo personal como una producción permanente de saberes y conocimientos, a partir de las historias de vida en todos los ámbitos socio-comunitarios. Así como de instrumentos mediadores que regulan y orientan la relación con el mundo 
66 La visión de mundo impuesta por la colonización no consideró la dimensión simbólica espiritual propia de la visión de los pueblos indígenas originarios.

externo, como la simbología, las lenguas, las manifestaciones culturales, entre otras.

\section{Propuesta de educación popular latinoamericana liberadora de Freire}

Dentro de las propuestas de Paulo Freire, se rescata la de pedagogía liberadora y problematizadora, que desarrolla una conciencia crítica y de actitudes reflexivas, orientada a generar cambios estructurales en los seres humanos y su entorno. Esta propuesta sostiene que la educación debe ser un proceso de comprensión crítica, de concienciación, sobre la realidad y la dominación que se vive, propiciando un proceso de liberación. La educación, en estos términos, se da a partir de un ejercicio de problematización crítico de la realidad, en el que se pregunta, reflexiona, investiga, a partir del diálogo de una comunidad.

La metodología de la problematización que se trata de recuperar para el nuevo Currículo Base es fuertemente contextual e histórica, pues los sujetos deben tomar conciencia sobre el lugar y contexto en que viven, vinculado a un momento histórico presente, en el sentido de que es un espacio de lucha y de opciones de construcción. En este sentido hay que puntualizar que esta propuesta educativa no parte del espejismo de la neutralidad, sino de una opción política clara por los pobres y excluidos, que ha sido un punto central en la educación popular.

El acto educativo se concibe como una interacción recíproca y complementaria entre el estudiante, el maestro/a y el entorno. Este proceso se da desde una acción dialógica liberadora ${ }^{25}$. Así, la producción y apropiación del conocimiento está orientada a la trans-

\footnotetext{
${ }^{25}$ Para Paulo Freyre el diálogo se convierte en un elemento esencial del proceso educativo, como práctica de libertad. A su vez, deja de ser un acto mecánico donde se depositan ideas de un sujeto a otro, para convertirse en un encuentro comunicativo dinámico que propicia la reflexión y la acción de las personas orientadas hacia el mundo. Debe ser transformador y humanizador.
}

formación de la realidad y la lucha por la liberación de la conciencia, el cuestionamiento a las inequidades económicas y políticas, el trabajo libre, la desalienación y la afirmación de los seres humanos como personas que viven en comunidad. En este sentido, para la educación socio-comunitaria productiva, el diálogo se convierte en un elemento esencial del proceso educativo, como práctica de libertad, siendo el encuentro que solidariza la reflexión y la acción de las personas en la búsqueda de la transformación.

\section{Principios de la educación}

El modelo educativo asume los siguientes principios, base de los fundamentos teóricos, en los que se concreta el currículo de la educación boliviana, en términos de la Constitución política (2008):

- Educación descolonizadora, liberadora, revolucionaria, antiimperialista y transformadora.

- Educación comunitaria, democrática, participativa y de consensos.

- Educación intracultural, intercultural y plurilingüe.

- Educación productiva, territorial, científica, técnica tecnológica y artística.

\section{Educación descolonizadora, liberadora, revolucionaria, antiimperialista y transformadora}

La colonización encierra las formas más diversas de dominio y sometimiento económico, político y cultural de un grupo de personas, sociedad o Estado sobre otras, para apoderarse de su riqueza material y espiritual, provocando procesos profundos de transculturación, donde la cultura hegemónica destruye la cultura propia de cada pueblo o nación dominada imponiéndose como hegemónica y mecanismo de perpetuación de la exclusión y discriminación.

La visión de mundo impuesta por la colonización no consideró la dimensión simbólica espiritual propia de la visión de los pueblos indígenas originarios, por el contrario la convirtió en un conjunto de elementos que fueron manipulados y manejados al servicio del "progreso”. En consecuencia, la educación descolonizadora, liberadora, revolucionaria y transformadora valoriza y legitima los saberes, conocimientos y valores de los pueblos indígena originario, como expresión de la identidad plurinacional y de sus derechos patrimoniales, incorporando en el currículo los conocimientos pluriculturales 
del pueblo boliviano, al igual que los conocimientos actualizados del saber latinoamericano y mundial.

Asimismo, cuestiona y rechaza el dominio, la hegemonía, la dogmatización y globalización sociocultural y económica neoliberal. La nueva educación promueve la Revolución Democrática Cultural del pensamiento y el saber que transforma la visión etnocéntrica, capitalista y occidental, en la perspectiva de contribuir a la transformación social, cultural, política y económica del Estado Plurinacional.

En ese entendido, la educación descolonizadora lidia contra todo tipo de discriminación étnica, racial, social, cultural, religiosa, lingüística, política y económica, para garantizar el acceso y permanencia de las y los bolivianos en el sistema educativo, promoviendo igualdad de oportunidades y equiparación de condiciones, a través del conocimiento de la historia de los pueblos, de los procesos liberadores de cambio y superación de estructuras mentales coloniales, la revalorización y fortalecimiento de las identidades propias y comunitarias, para la construcción de una nueva sociedad.

\section{Educación comunitaria, democrática, participativa y de consensos}

La educación comunitaria es un proceso de convivencia con pertinencia y pertenencia al contexto histórico, social y cultural en que tiene lugar el proceso educativo. Esta forma de educación mantiene el vínculo con la vida desde las dimensiones material, afectiva y espiritual, generando prácticas educativas participativas e inclusivas que se internalizan en capacidades y habilidades de acción para el beneficio comunitario. Se orienta a la transformación sociocultural, política y económica donde se aprende y práctica el entramado cultural del Vivir Bien, sin perder su condición de agente de cambio; las y los estudiantes aprenden todas las prácticas socio-comunitarias en un marco participativo, democrático y de consensos.

Con la educación democrática se generan espacios de equidad e igualdad de oportunidades y participación, apunta a la democratización del acceso al conocimiento y a la práctica del poder promoviendo el ejercicio y la exigibilidad de los derechos, así como el cumplimiento de deberes. A su vez, la práctica de los valores socio-comunitarios se transforma en relaciones de convivencia socialmente conscientes. Sumado a lo anterior, propicia la transmisión sociocultural en la comprensión holísti-

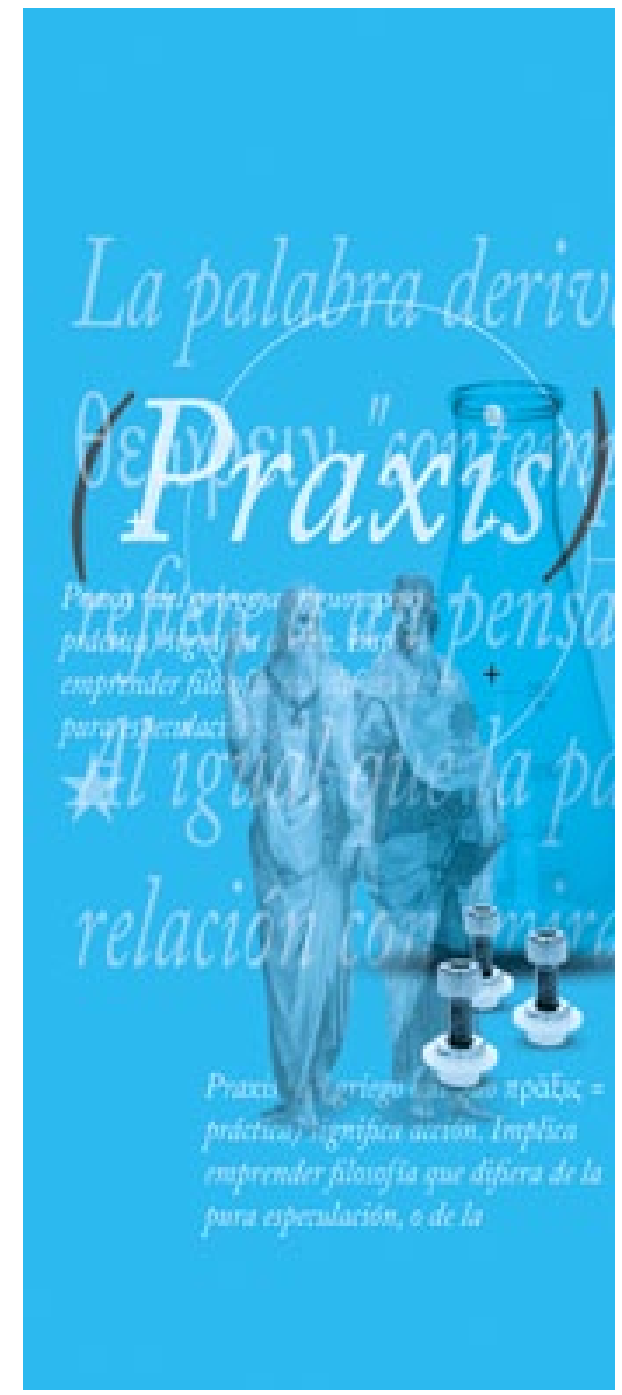


ca de la vida y la cohesión social con la naturaleza y el cosmos. Ser comunitario no depende de la genética, sino de la convivencia; por ello, la educación comunitaria respalda la participación social como una instancia determinante en la toma de decisiones y el ejercicio del poder en el quehacer educativo.

\section{Educación intracultural, intercultural y plurilingüe}

La educación intracultural, intercultural y plurilingüe articula el Sistema Educativo Plurinacional desde la recuperación, el potenciamiento y desarrollo de los saberes conocimientos y las lenguas propias de las naciones indígenas originarias, promoviendo la interrelación y convivencia complementaria con otras culturas. La educación intracultural es un proceso multireferencial ${ }^{26}$ de aprendizaje de lo propio, el cual promueve la autoafirmación, el reconocimiento, fortalecimiento, cohesión y desarrollo de la plurinacionalidad, a través del estudio y puesta en práctica de los saberes, conocimientos y el ejercicio de los valores socio-comunitarios, contribuyendo a la afirmación de las identidades y al desarrollo de la ciencia y tecnología propias; donde las culturas y lenguas indígenas originarias son valoradas y desarrolladas en el marco del pluralismo de los saberes y conocimientos, superando de esta manera la colonialidad y el pensamiento homogeneizador.

El fortalecimiento de la intraculturalidad, en relación dialógica, reciproca y complementaria con la diversidad cultural del mundo, promueve una educación intercultural que se define como una multiplicidad de procesos históricos que derivan en un encuentro entre culturas, superando las inequidades derivadas de las estructuras coloniales. Los currículos de los sistemas educativos anteriores no superaron las imposiciones civilizatorias de unas culturas sobre otras, por ello la educación intercultural planteada en este modelo, promueve la producción de saberes y conocimientos sin distinciones jerárquicas para el bien común.

La educación plurilingüe es un instrumento de reivindicación que promueve el reconocimiento y desarrollo de las lenguas con énfasis en las originarias, que aporta a la intraculturalidad como una forma de descolonización,

${ }^{26}$ Lo multireferencial se interpreta como la transmisión cultural intergeneracional condicionada por contextos históricos y geográficos, por la incorporación de elementos culturales apropiados, por la innovación de acuerdo con los cambios socioculturales, económicos y políticos, y el cambio que se genera a partir de las interfaces culturales. y a la interculturalidad mediante el establecimiento de relaciones dialógicas que superan los niveles comunicativos y que se plasman en la vida cotidiana y en los procesos de transformación social, económica y política.

En el currículo del SEP (Sistema Educativo Plurinacional), el lenguaje en general y las lenguas en particular ya no son abordados como objetos de análisis gramatical, ni sólo como un instrumento de comunicación, sino a partir de una experiencia activa de uso y producción permanente de significados en la vida cotidiana, superando la situación heteroglósica ${ }^{27}$ en la que se encuentra la gestión y desarrollo curricular. Las lenguas extranjeras, además de su carácter instrumental para acceder a saberes, conocimientos y descubrimientos de otros ámbitos culturales del mundo, nos permiten acceder a lógicas de pensamiento transfronterizo, ampliando las estrategias de comunicación y convivencia intercultural.

Por tanto, la educación plurilingüe garantiza y propicia el aprendizaje de una lengua originaria para todos los bolivianos, por ser parte esencial de la identidad cultural que expresa los saberes y conocimientos de la cultura. En el actual modelo educativo, las lenguas se convierten en las herramientas fundamentales de comunicación, desarrollo y producción de saberes y conocimientos, abordados en toda la estructura curricular desde el nivel de Educación Inicial en familia comunitaria, hasta el nivel de Educación Superior. A partir de ello, todos los niveles de formación asumen la responsabilidad de realizar una planificación lingüística y concretar la implementación de las lenguas originarias en el currículo en las diferentes regiones sociolingüísticas.

\section{Educación productiva territorial, científica, técnica tecnológica y artística}

La educación productiva territorial es parte sustancial del proceso educativo y está orientada a la transformación de la matriz productiva, desarrollando capacidades, habilidades y destrezas que contribuyen a la producción de bienes tangibles e intangibles, de manera sustentable, promoviendo procesos de producción, conservación, manejo y defensa de los recursos naturales, en el marco de las actividades productivas

\footnotetext{
${ }^{27}$ Situación sociolingúística en la que una lengua se superpone a otras lenguas en cuanto al uso en contextos formales y cotidianos.
} 
locales y regionales, y el fortalecimiento de la gestión territorial comunitaria, de acuerdo a los postulados del Estado Plurinacional. La educación productiva territorial articula a las instituciones educativas con las actividades económicas de la comunidad.

La educación científica, técnica, tecnológica, desarrolla ciencia y tecnología a partir de la investigación aplicada a la producción tangible e intangible, desde la valoración y desarrollo de los saberes y conocimientos de los pueblos y naciones indígenas originarios, orientada al despliegue de un Estado plurinacional soberano. La educación artística desarrolla capacidades y habilidades de expresión, creatividad y sensibilidad personal y social, encarando una multiplicidad de desafíos y soluciones a las demandas que vinculan la existencia material y las experiencias espirituales. La incorporación de tecnologías de comunicación e información en educación, se fundamenta en la posibilidad de crear nuevos entornos creativos y expresivos que faciliten la posibilidad de desarrollar nuevas experiencias pedagógicas desde dos ámbitos: como fin, para ofrecer a las y los estudiantes bases de la educación técnica-tecnológica adecuada a cada nivel; y como medio, para convertirla en un instrumento de aprendizaje, acceso y difusión del desarrollo de la ciencia compatibles con su uso e impacto en la comunidad.

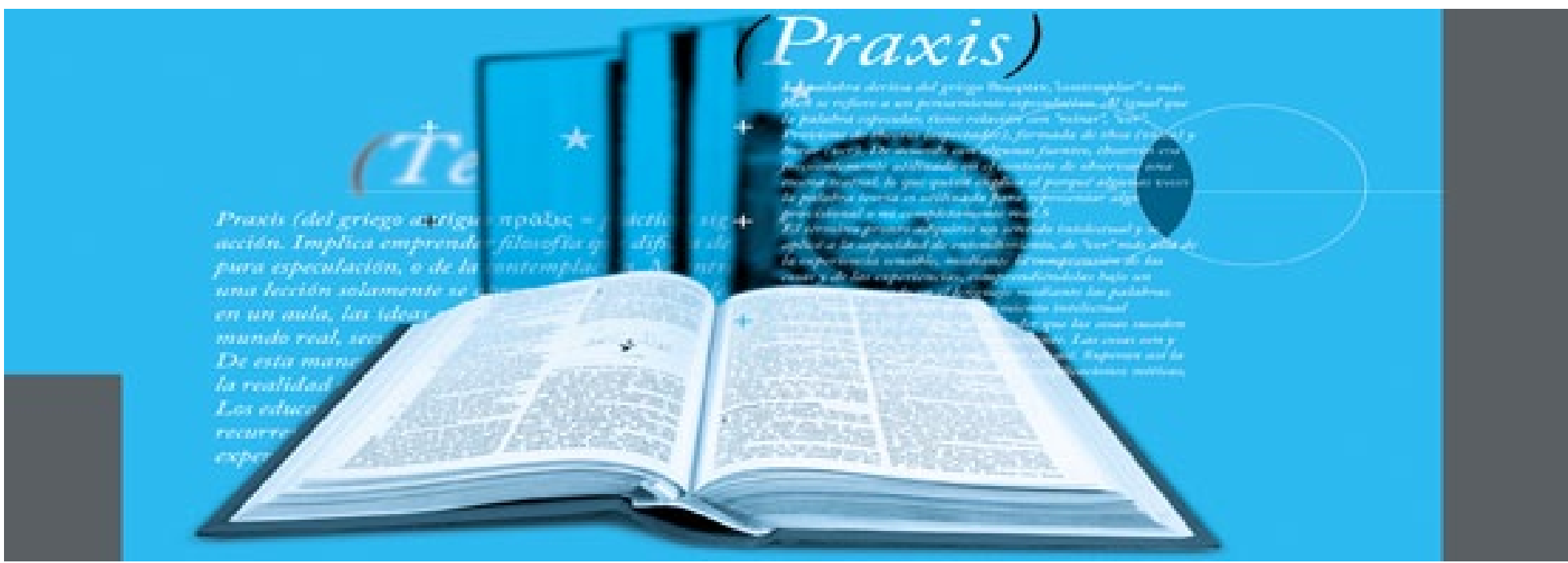




\section{Referencias}

Arnold, Denise y otros. (2004). El rincón de las cabezas. Luchas textuales, educación y tierras en los Andes. La Paz: ILCA - UMSA.

Asamblea Constituyente, Honorable Congreso Nacional. (2009). Constitución Política del Estado. Versión Oficial. La Paz: Distribución gratuita.

Álvarez De Zayas, Carlos M. (1992). La escuela en la vida. La Habana: Editorial Félix Várela.

Álvarez De Zayas, Carlos M. (2000). El diseño curricular. Cochabamba: PROMEC-UMSS.

Barnadas, Josep. (1976). Sistema Educativo Plurinacional. Historia de la Iglesia Católica en

Bolivia. La Paz: La juventud.

Bordieu, Pierre y Wacquant Loic, J. D. (1990). El oficio del sociólogo. México: Siglo XXI, p. 371.

Bordieu, Pierre y Wacquant Loic, J. D. (1995). Respuestas por una antropología reflexiva. México: Grijalbo.

Bloque Educativo Indígena Originario, CNC. (2008). Educación, cosmovisión e identidad. Una propuesta de diseño curricular desde la visión de las naciones y pueblos indígenas originarios. Bolivia: Preview Gráfica.

Camilloni, R.W., y otros. (2001). La evaluación de los aprendizajes en el debate didáctico contemporáneo. Argentina: Paidós.

Consejo Nacional de Educación (CONED). (2005). Documento de trabajo I, II y III. Congreso Nacional de Educación 2005: Resumen de los congresos departamentales. La Paz: Industrias Lara Bisch S. A.

Concejo Educativo de La Nación Quechua - CENAQ. (2003). Procesos de Participación Comunitaria de la Nación Quechua. Acciones educativas, ํำ 2. Sucre: Talleres Túpac Katari.

Consejo Educativo Aymara. (2003). Conquistas sociales del pueblo Aymara en la educación boliviana. La Paz: VEEA.
CSUTCB. (2005). Bolivia. Educación Fundamental en el Beni. Boletín Indigenista, Vol. XVI, No 2 y 3. México: Instituto Indigenista Interamericano, pp. 136-140.

CSUTCB. (2005-Abril). Pachakuti Educativo. Propuesta de la CSUTCB al II Congreso Nacional de Educación. Basada en el modelo de Ayllu. La Paz: Artes Gráficas.

Claure, Karen. (1989). Las escuelas indigenales: Otra forma de resistencia comunitaria. La Paz: Hisbol.

Chateau, Jean. (1996). Los grandes pedagogos. México: Fondo de Cultura Económica.

Choque, Roberto. (1992). Sociedad y economía colonial. La Paz: Hisbol.

Choque Canqui, Roberto y Quisbert, Cristina. (2006). Educación indigenal en Bolivia. Un siglo de ensayos educativos y resistencias patronales. La Paz: IBIS.

Choque Canqui, Roberto y Ticona Alejo, Esteban. (1996). Jesús de Machaga la marca rebelde. Sublevación y masacre de 1921. La Paz: CIPCA y CEDOIN.

Choque Canqui, Roberto y otros. (1996). Educación Indígena: ¿Ciudadanía o colonización? La Paz: Ediciones Aruwiyiri.

Dussela, Enrique. (1983). Historia de la iglesia en América Latina; Coloniaje y liberación 1492 -1983. España: Editorial Mundo Negro - Esquila Misional.

Dussela, Enrique. (1992). 1492. El encubrimiento del otro. Hacia el origen del mito de la modernidad. Madrid: Nueva Utopía.

Dussela, Enrique. (1998). Ética de la liberación en la edad de la globalización y exclusión. México: Universidad Autónoma Metropolitana Iztapalapa.

Dussela, Enrique. (2001). Hacia una política crítica. Bilbao: Descleé de Brouwer.

Dussela, Enrique. (2006). 20 proposiciones de política de la liberación. Bolivia: Colección letra viva. 
Escobari de Querejazú, Laura. (2009). Historia de la alfabetización en Bolivia. Época colonial Siglos XVI-XVII. En Galia, Domic. (Coord.). Estudios bolivianos, 15. Políticas públicas educativas. La Paz: UMSA.

Espinoza, Waldemar. (1987). Los incas, economía, sociedad y Estado en la era del Tawantinsuyo. Lima: Amaru Editores.

Freire, Paulo. (1970). Pedagogía del oprimido. México: Siglo XXI.

Freire, Paulo. (1991). Cartas a quien pretende enseñar. España: Siglo XXI.

Freire, Paulo. (1993). Pedagogía de la esperanza. México: Siglo XXI.

Gutiérrez, Ramiro. (2005). El proyecto educativo indígena y la mejora de la gestión en unidades

educativas indígenas de Bolivia, Memoria del Diplomado Cultura, Lengua y Educación en los Andes y la Amazonia. Cochabamba: PROElB-Andes, Universidad Mayor de San Simón.

Huanacuni Mamani, Fernando. (2010). Vivir Bien/ Buen Vivir. Filosofía, políticas, estrategias y experiencias regionales. La Paz: Producción: III-CAB.

Illescas, José, y Gonzales Jimena. (2002). Acerca de la educación en el mundo originario pre-inca en el territorio donde se formaría el Tahuantisuyo y el Qollasuyo. Bolivia: Centro de Documentación e Información.

Illescas, José, y Gonzales Jimena. (2003). Acerca de la Ontología, Gnoseología y Epistemología de lo Humano o del Ser en su Estar siendo-ocurriendosucediendo siempre no más. Bolivia: Universidad Autónoma Gabriel Rene Moreno. Ediciones TukuyRiqch’arina.

Instituto Internacional de Integración. (2008). Diseño y desarrollo curricular. Plural. Integra educativa. Revista de investigación educativa, № 2 . La Paz.

Muñoz, Jacob y Velarde, Julián. (2000). Compendio de Epistemología. Madrid: Trotta. .
Mamani, Carlos. (1991). Taraqu 1886-1935: Masacre, guerra y "Renovación” en la biografía de

Eduardo L. Nina Qhispi. Aruwiyiri. La Paz.

Medina, Javier. (2008). Ch'ulla y Yanantin. Las dos matrices de civilización que constituyen a

Bolivia. La Paz: Garza Azul Impresores y Editores.

Suma, Qamaña. (S.F). La comprensión indígena de la Buena Vida.

Mier Aliaga, Carlos. (2009). El modelo del Socialismo Comunitario. La Paz: Talleres COMA, I.

Ministerio de Educación. (1969). Reforma Educativa. La Paz: Consejo Supremo de Educación, Dirección Nacional de Planificación Educativa.

Ministerio de Educación. (2003). Diseño curricular para el nivel de educación infantil. La Paz.

Ministerio de Educación. (2005). Diseño curricular para el nivel de educación primaria. La Paz: Paper King S.R.L.

Ministerio de Educación y Culturas. (2006). Anteproyecto de Nueva Ley de la Educación Boliviana "Avelino Siñani y Elizardo Pérez". Documento consensuado y aprobado por el Congreso Nacional de Educación. Sucre 10 al 15 de Julio de 2006. Santa Cruz: El Deber.

Ministerio de Educación y Culturas. (2007). Políticas de descolonización de las prácticas educativas. Documentos de trabajo. Bolivia.

Ministerio de Planificación del Desarrollo. (2007). Plan Nacional de Desarrollo. "Bolivia digna, soberana, productiva, democrática para Vivir Bien”. La Paz: Artes Gráficas Sagitario.

Ministerio de Relaciones Exteriores. (2010). La tierra no nos pertenece, nosotros pertenecemos a la Tierra. Bolivia.

Morales Ayma, Evo. (S.F). Diplomacia por la vida. Bolivia. 
Ministerio de Culturas, Vice Ministerio de Descolonización. Unidad de Gestión y Coordinación de Políticas Públicas de Descolonización. (2009). Principios del servidor público del Estado Plurinacional de Bolivia. Bolivia.

Morín, Edgar. (2000). El desafío del siglo XXI. Unir los conocimientos. Jornadas temáticas concebidas y animadas. Bolivia: Plural Editores.

Morín, Edgar. (2001). Los siete saberes necesarios para la educación del futuro. Barcelona: Paidós.

Morín, Edgar. (2001). La Cabeza bien puesta. Repensar la reforma. Repensar el pensamiento. Buenos Aires: Ediciones Nueva Visión.

Panikkar, Raimon. (2008). La puerta estrecha del conocimiento. Barcelona: Herder.

Patzi, Paco Félix. (2004). Sistema comunal. Una propuesta alternativa al sistema liberal. La Paz: CEA.

Pérez, Elizardo. (1962). Warisata. La escuela ayllu. Bolivia: Gráfica E. Burillo.

Puente, Rafael. (2011). Recuperando la memoria. Una historia crítica de Bolivia. T. 1. La Paz: Colonia Piraí.

Reyeros, Rafael. (1952). Historia de la educación boliviana 1825-1898. La Paz: Ed. Universo.

Salazar Mostajo, Carlos. (1976). La escuela ayllu y las concepciones educativas de Elizardo Pérez. La Paz.

Salazar Mostajo, Carlos. (1992). La Tayka. Teoría y práctica de la escuela Ayllu. La Paz: Librería Editorial Juventud.

Salazar Mostajo, Carlos. (1997) ¡Warisata mía! y otros artículos polémicos. La Paz: Librería Editorial Juventud.
Stenhouse, Lawrence. (1991). Investigación y desarrollo del currículo. Madrid: Morata.

Suarez Arnez, Faustino. (S.F). Historia de la educación en Bolivia. Manuscrito sin editar.

Ticona, Alejo Esteban, y Albo, Xavier. (1997). La lucha por el poder comunal. Vol. 3. Serie Jesús de Machaca: la marka rebelde. La Paz: Cedoin/Cipca.

UMSA. (2007). Historia. Revista de la carrera de historia. Número monográfico, dedicado a la Historia de la Educación Boliviana. La Paz: Creativa.

Unidad Nacional de las Naciones Indígenas Originarias. (2004). Por una educación Indígena Originaria. Hacia la autodeterminación ideológica, políti$c a$, territorial y sociocultural. Bolivia: CONAMAQ, CSUTCB, CIDOB, APG, CSCB, FNMCB-BS.

Vygotski, L. (1972). El problema de la periodización por etapas del desarrollo del niño. Problemas de Psicología, 2, pp. 114-123.

Vygotski, L. (1979). Desarrollo de los procesos psicológicos superiores. Barcelona: Crítica.

Vygotski, L. (1988). Teoría del desarrollo cultural de las funciones psíquicas. Pensamiento y lenguaje. México: Ediciones Quinto Sol.

Zambrana, Amilcar. (2009). Prácticas de curación en el marco de la socialización territorial de niñosen el pueblo tsimane. En El vuelo de la luciérnaga. Revista semestral para el diálogo entre personas de pueblos nacionalidades diferentes, No 2. Lima: UNICEF/Proyecto EIBAMAZ.

Zavaleta, René. (1994). Lo nacional popular en Bolivia. México: Siglo XXI.

Zemelman, Hugo. (2003). Los horizontes de la razón II. Historia y necesidad de utopía. España: Anthropos. 